\title{
Comportamiento saboteador en mediación internacional: la fragilidad del proceso sirio
}

\author{
Spoiling behavior in international mediation: \\ The fragility of the Syrian process
}

\author{
JUSAIMA MOAID-AZM PEREGRINA \\ Universidad de Granada
}

\section{Cómo citar/Citation}

Moaid-azm Peregrina, J. (2020). Comportamiento saboteador en mediación internacional: la fragilidad del proceso sirio. Revista Española de Ciencia Política, 54, 95-120. Doi: https://doi.org/10.21308/recp.54.04

\section{Resumen}

El proceso mediador para Siria ha sido definido por su fragilidad reiteradamente. Esta fragilidad no solo deriva de su incapacidad para producir resultados tangibles, sino también de otras dimensiones como su inestabilidad, la falta de imparcialidad de su estructura mediadora o su falta de representatividad y capacidad de acción, todas ellas estudiadas más tangencialmente. El propósito de este artículo es determinar los factores explicativos de estas otras dimensiones de la fragilidad del proceso. Para ello, en primer lugar, partiendo de la literatura del spoiler, se operacionaliza el comportamiento spoiling, distinguiendo los actos violentos de los no violentos. En segundo lugar, se analizan sus efectos sobre el proceso, identificando la relación entre ellos y la fragilidad. En tercer lugar, se evalúan con esta óptica los períodos de los cuatro enviados especiales para Siria asignados por la ONU hasta la fecha (diciembre, 2019). Los resultados de la investigación muestran que el comportamiento spoiling violento en el proceso mediador para Siria explica las reacciones drásticas tanto de la propia actividad mediadora (suspensión de la misión de observación o posposición de la apertura de conversaciones) como de las partes intervinientes (retirada o suspensión de las conversaciones), mientras que el comportamiento no violento tiende a atacar el proceso de una forma más sutil, amenazando su relevancia o imparcialidad. La consecuencia más evidente es un proceso mediador frágil, capaz de cuestionar la capacidad de la mediación internacional frente a conflictos armados de naturaleza intratable.

Palabras clave: Siria, mediación, spoiler, fragilidad, violencia.

\section{Abstract}

The Syrian mediation process has repeatedly been characterized by its fragility. This fragility does not only stem from its inability to produce tangible results but it also rests on other 
dimensions such as its instability, the lack of impartiality of its mediation structure, or its lack of representativeness and capacity for action, all of which have been studied more tangentially. The purpose of this article is to determine the explanatory factors of these other dimensions of the fragility of the process. In order to do so, and based on the spoiler literature, it first operationalizes the spoiling behavior, distinguishing violent acts from non-violent ones. In the second place, their impact on the process is analyzed, identifying the relationship between them and fragility. In the third place, the mandates of the four Special Envoys assigned by UN to date (January 2020) are evaluated from this perspective. The results of this research show that the violent spoiling behavior in the Syrian mediation process explains the drastic reactions both by the mediating activity itself (suspension of the observation mission, withdrawal of the mediator or postponement of the opening of talks) and by the intervening parties (withdrawal or suspension of conversations), while non-violent behavior tends to attack the process in a more subtle way, threatening its relevance or impartiality. The most evident consequence is a weak mediation process, that may raise doubts on the ability of international mediation in the face of intractable armed conflicts.

Keywords: Syria, mediation, spoiler, fragility, violence.

\section{INTRODUCCIÓN}

El año 2011 marcó el comienzo de uno de los conflictos armados más cruentos de Oriente Próximo. Las represivas respuestas gubernamentales del presidente Bashar al-Asad a las manifestaciones y protestas iniciadas por la población siria dentro del proceso conocido como la Primavera Árabe, inauguraron todo un ciclo de violencia que se intensificó a raíz de los posicionamientos e intervenciones regionales e internacionales.

En paralelo al conflicto armado, comenzaron a producirse los primeros esfuerzos ligados a la apertura de un cauce diplomático que abriese el diálogo político y pusiese fin a la violencia. En agosto de 2011, la organización de la Liga Árabe (LA), dada su visión regional y aparentemente más cercana al conflicto, elaboró un plan de acción y tomó las riendas de la mediación, pero su fracaso en enero de 2012 dio entrada a Naciones Unidas (ONU). Entonces, en el seno del Consejo de Seguridad (CS), Rusia y China vetaron un borrador de resolución presentado por Francia, Reino Unido (RU) y Estados Unidos (EE. UU.) que apoyaba el establecimiento de un Gobierno de unidad y la apertura de una transición política en Siria. Esto originó un impasse frente al cual la Asamblea General solicitó a la Secretaría General el nombramiento de un enviado especial que, empleando los buenos oficios y la mediación, permitiese el desarrollo de un proceso político. Consecuentemente, fueron nombrados Annan - en el cargo entre febrero y agosto de 2012—, Brahimi —entre septiembre de 2012 y mayo de 2014_, De Mistura —entre julio de 2014 y noviembre de 2018 - y Pedersen —en el cargo desde enero de 2019—.

Estas mediaciones conforman el cauce oficial, sin éxito aparente, por el que han transcurrido el conjunto de esfuerzos ligados a la consecución de paz y diálogo político 
en el marco de la crisis siria. Sus actuaciones han llevado a la literatura a cuestionar los factores que condenan al fracaso este proceso, prestando especial atención a su incapacidad para conseguir unos resultados tangibles (el cumplimiento de una hoja de ruta, un cese de hostilidades sostenido o un acuerdo político, entre otras opciones). En consecuencia, el proceso sirio ha sido calificado como frágil reiteradamente.

No obstante, esta fragilidad no se manifiesta exclusivamente en su incapacidad para producir resultados, sino también en la inestabilidad del proceso y la discontinua celebración de conversaciones de paz, en la pérdida de relevancia del proceso por la ausencia de actores clave o en su falta de imparcialidad motivada por las injerencias de los actores en la estructura mediadora. Así, este artículo parte de la siguiente pregunta de investigación: ¿qué factores explican la fragilidad del proceso mediador para Siria y qué impacto tiene el comportamiento de las partes sobre el mismo? Para responder a esta pregunta nos planteamos los siguientes objetivos específicos: a) identificar el marco teórico pertinente para el análisis del comportamiento de las partes en el seno del proceso sobre la base de los estudios del conflicto armado y la paz; b) operacionalizar los comportamientos de las partes enfrentadas que demuestran impactar sobre el proceso, y c) evaluar el efecto de este comportamiento sobre el proceso mediador.

Esta investigación parte de la hipótesis de que la adopción de un comportamiento de sabotaje por las partes enfrentadas en los tres niveles del conflicto - internacional, regional e interno- determina la fragilidad del proceso mediador en sus distintas dimensiones. Este análisis queda justificado no solo por su contribución a la incipiente literatura del proceso mediador para Siria, sistematizando su fragilidad e identificando los comportamientos que la provocan, sino también porque, aunque ceñido a Siria, puede apuntar algunas tendencias generales del estado de la mediación actual en el marco de conflictos armados, dado el especial impacto que las dinámicas de polarización del sistema internacional y regional tienen sobre este proceso.

El artículo adopta, en primer lugar, un enfoque teórico que explica el comportamiento de las partes dentro del proceso mediador para Siria; en segundo lugar, ofrece una metodología que operacionaliza este comportamiento, poniéndolo en relación con su potencial impacto sobre el proceso; en tercer lugar, identifica estos actos en las sucesivas rondas de mediación, evaluando sus efectos. Por último, resume los resultados más relevantes del análisis.

\section{MARCO TEÓRICO: EL SPOILER O SABOTEADOR DE LA PAZ}

En su análisis de la mediación de Annan, Greig (2013) advierte de los peligros que ha supuesto el incremento del número de actores para la efectividad del proceso, por cuanto dificulta la coordinación de las comunicaciones por el mediador, ańade problemas de compromiso respecto de la consecución e implementación de acuerdos, e incrementa el riesgo de surgimiento de saboteadores, dado el mayor número de agendas en conflicto.

En la dirección de los estudios de los factores que frustran los esfuerzos de paz, cobra especial relevancia la figura del saboteador de la paz o spoiler. Esta figura fue 
propuesta por primera vez por Stedman (1997) para explicar un tipo de comportamiento que las partes enfrentadas pueden adoptar en un proceso de paz. Su definición -líderes o partes [del conflicto] que con el proceso de paz ven amenazados su poder, posición e intereses, y usan la violencia para socavar el proceso (ibid.: 5) - ha sido revisada desde entonces bajo distintos criterios. En su ámbito subjetivo, no existe consenso en la definición de qué partes en el conflicto pueden ser consideradas spoilers. En su versión original, Stedman (ibid.) entendió que el concepto de spoiler debía referirse exclusivamente a los actores internos enfrentados, con una naturaleza eminentemente no estatal (Greenhill y Major, 2007; Nilsson, 2008; Pearlman, 2009 asumen esta línea). Sin embargo, la propia evolución en las formas de hacer la guerra obliga a ampliar el foco de atención con el objetivo de abarcar comportamientos de actores hasta el momento inéditos y que, sin embargo, muestran voluntad y capacidad de sabotear decisivamente un proceso de paz.

Así, algunos autores optan por ampliar la definición de spoiler a todo actor que, aunque geográficamente externo al conflicto, emplea estrategias saboteadoras o apoya a actores internos que actúan como tal, pudiendo incluir, por tanto, a terceros Estados, aliados políticos, empresas multinacionales, grupos en la diáspora o cualquier otro que reúna las características (Newman y Richmond, 2006; Conversi, 2006; Cochrane, 2008). En esta línea, han participado en el proceso mediador para Siria tres grupos de actores que sobrepasan la óptica interna, correspondientes con los tres ámbitos del conflicto, internacional, regional e interno, y que no solo intervienen en el proceso, sino que además demuestran disponer de capacidad para su definición y potencial obstaculización.

En el ámbito de los medios empleados, originariamente Stedman (1997) abarcó exclusivamente el empleo de técnicas violentas que socavasen el proceso de paz. A partir de esta línea, una parte de la literatura ha centrado el análisis en el impacto que tienen las estrategias saboteadoras violentas sobre los procesos de paz, bajo qué condiciones los hacen más vulnerables y los desestabilizan o las motivaciones que mueven a las partes al empleo de estas estrategias (Licklider, 2001; Zahar, 2006; Blaydes y De Maio, 2010; Reiter, 2016). Paradójicamente, a pesar de que el objetivo de este comportamiento sea socavar el proceso, las partes, a menudo, no lo descartan, toda vez que terminan empleándolo como una estrategia de guerra más con el fin de obtener mayores recursos militares, mayores apoyos, aliados o reconocimiento, más tiempo, forzar una victoria mientras se demandan mayores concesiones a las otras partes, acceso a organizaciones internacionales o regionales y a sus recursos o, incluso, evitar sanciones. Estos «objetivos desviados» del propósito de la negociación (Richmond, 2006) han llevado a considerar igualmente estrategias no violentas con capacidad de sabotear el proceso (Newman y Richmond, 2006; Pearlman, 2009; Golan y Sher, 2019).

Así, Zahar (2003: 114) defiende que el spoiler típico actuará o negándose sistemáticamente a la negociación o accediendo al acuerdo, para posteriormente incumplir sus promesas de implementación. A estos actos se agregan otras estrategias que pueden afectar la fortaleza del proceso y, eventualmente, conducirlo al fracaso: la asimetría en el estatus de las partes, en cuyo seno juega el veto a la contraparte como interlocutor 
legítimo, o las dinámicas de participación (Aggestan, 2012), donde la exclusión de otros actores o rechazar la propia participación atacan la inclusión del proceso y, por ende, la consistencia de un eventual acuerdo (Linklider, 2001; Blaydes y De Maio, 2010; Nilsson, 2012).

Una buena parte de la literatura centrada en el análisis de los efectos de los comportamientos saboteadores asume que estos actos determinan finalmente el fracaso de los procesos (Nilsson y Söderberg, 2011). Sin embargo, esta relación causal, que observa el spoiling como un juego de suma cero en el que solo cabe producir dos opciones, fracaso o éxito, no solo sufre de falta de precisión sino que además resulta excesivamente determinista. En este sentido, el impacto del sabotaje violento no necesariamente produce los mismos efectos sobre el proceso que el sabotaje no violento, de forma que la finalidad originaria del concepto de sabotear un proceso puede manifestarse de varias formas en función del tipo de estrategia saboteadora empleada. De hecho, Newman y Richmond (2006) señalan que es importante diferenciar entre el uso del sabotaje violento y no violento para modificar un proceso negociador y su uso para destruirlo, pues su impacto puede ser radicalmente distinto. Por ejemplo, el spoiler interno al proceso (Stedman, 1997) empleará normalmente estrategias diseńadas para lo primero, más que para lo segundo, en la medida en que reconoce los beneficios que el proceso puede ofrecerle y accede a él (Newman y Richmond, 2006: 18).

En definitiva, el estudio del saboteador ofrece un nuevo enfoque holístico de los comportamientos de las partes en el proceso mediador para Siria. La literatura sobre esta mediación muestra un proceso incapaz de producir resultados, pero paralelamente, sobre la incompatibilidad de sus agendas y la presencia de objetivos desviados, las partes adoptan un comportamiento saboteador que, en sus versiones violenta y no violenta, acaba debilitando el proceso. Esta fragilidad se manifiesta a través de distintas dimensiones que evidencian la estrecha relación del plano bélico y diplomático en la mediación siria como veremos en los apartados siguientes.

\section{METODOLOGÍA}

Desde el enfoque ofrecido por la literatura del spoiler, la hipótesis que articula el estudio defiende que los actos de sabotaje adoptados por las partes enfrentadas en el conflicto sirio sobre el proceso mediador determinan la fragilidad del mismo. El análisis provee un estudio de caso que toma como puntos de referencia los períodos de mediación de LA y ONU (vid. supra), examinando los comportamientos de las partes que adoptan una forma de sabotaje y el impacto de los mismos sobre la mediación. Para ello, en primer lugar, contrastando con la observación del proceso sirio los elementos generalmente aceptados como configuradores de un proceso mediador fuerte y capaz de producir resultados, se sistematiza la variable dependiente identificando las principales manifestaciones de la fragilidad: inestabilidad del proceso, falta de imparcialidad y unidad de acción, y falta de relevancia (tabla 1). En segundo lugar, se operacionaliza la variable causal a partir del análisis de fuentes primarias (entrevista de la autora con el 
anterior enviado especial De Mistura) y de la literatura como fuente secundaria, identificando aquellos comportamientos obstruccionistas que debilitan el proceso al producir alguna de las manifestaciones señaladas. Por último, se correlacionan las estrategias de sabotaje con el impacto que producen sobre el proceso mediador para Siria (tabla 1).

\section{Operacionalización del comportamiento saboteador en el proceso mediador para Siria}

A fin de identificar las estrategias de sabotaje empleadas en el proceso mediador para Siria se adoptan dos dimensiones atendiendo al escenario donde se producen y a la naturaleza violenta o no violenta de los actos que las componen. Por un lado, la dimensión indirecta comprende comportamientos violentos o de fomento de la violencia que, produciéndose en el plano bélico, impactan sobre el plano diplomático. Entre los primeros se incluyen actos que desprecian productos del proceso destinados a producir un cese de la violencia (como ceses de hostilidades, altos al fuego o treguas), actos violentos de especial letalidad (empleo de armamento químico) o, aún sin mediar compromiso, actos destinados a incrementar la violencia justo en el marco de unas conversaciones de paz. Entre los segundos se distinguen actos de fomento de la violencia, el aprovisionamiento logístico y militar a determinados actores y el desprecio a acuerdos de no militarización convenidos por aliados del nivel regional o internacional. Ambos comportamientos siembran profunda desconfianza entre las partes, lo que provoca reacciones extremas que tienden a desestabilizar el proceso. La posposición o suspensión de las conversaciones, la retirada de una parte o la suspensión de la misión de observación son manifestaciones indicativas de esta desestabilización.

Por otro lado, la dimensión directa integra estrategias que, produciéndose en el plano diplomático, lo instrumentalizan a través de dos variables: a) el apoderamiento estructural, y b) el apoderamiento relativo. El primero supone que un actor altera la estructura mediadora oficial del proceso, esto es, su mandato u objetivos, viciando la imparcialidad que se predica de la mediación o bien usurpando la oficialidad del proceso desarrollado por la ONU mediante la creación de un proceso paralelo cuyo desarrollo el saboteador pueda controlar y cuyos resultados estén en línea con su agenda. Por su lado, el segundo implica el empleo de la cuota de poder relativa del actor sobre el proceso para la obstrucción u modificación de aspectos clave del cauce oficial LA-ONU con el fin de modificarlo a conveniencia y alinearlo con la propia agenda. Para ello, el actor puede condicionar su participación en las conversaciones, exigiendo "peticiones irreales» (Reiter, 2016) u objetivos cuya consecución debiera producirse en el seno de una negociación; imponiendo un veto a la participación de otros actores clave para la finalidad del proceso o, ya en el seno del CS, vetar resoluciones clave que podrían reforzar la credibilidad, representatividad o, sencillamente, las posibilidades de éxito del mediador.

Este comportamiento provoca la fragilidad del proceso en dos sentidos. Por un lado, resta imparcialidad y unidad de acción al proceso cuando ataca o fagocita la estructura mediadora oficial y, por otro, reduce la relevancia del proceso al reducir su capacidad de afrontar el mandato o su grado de representatividad al excluir actores ineludibles. 


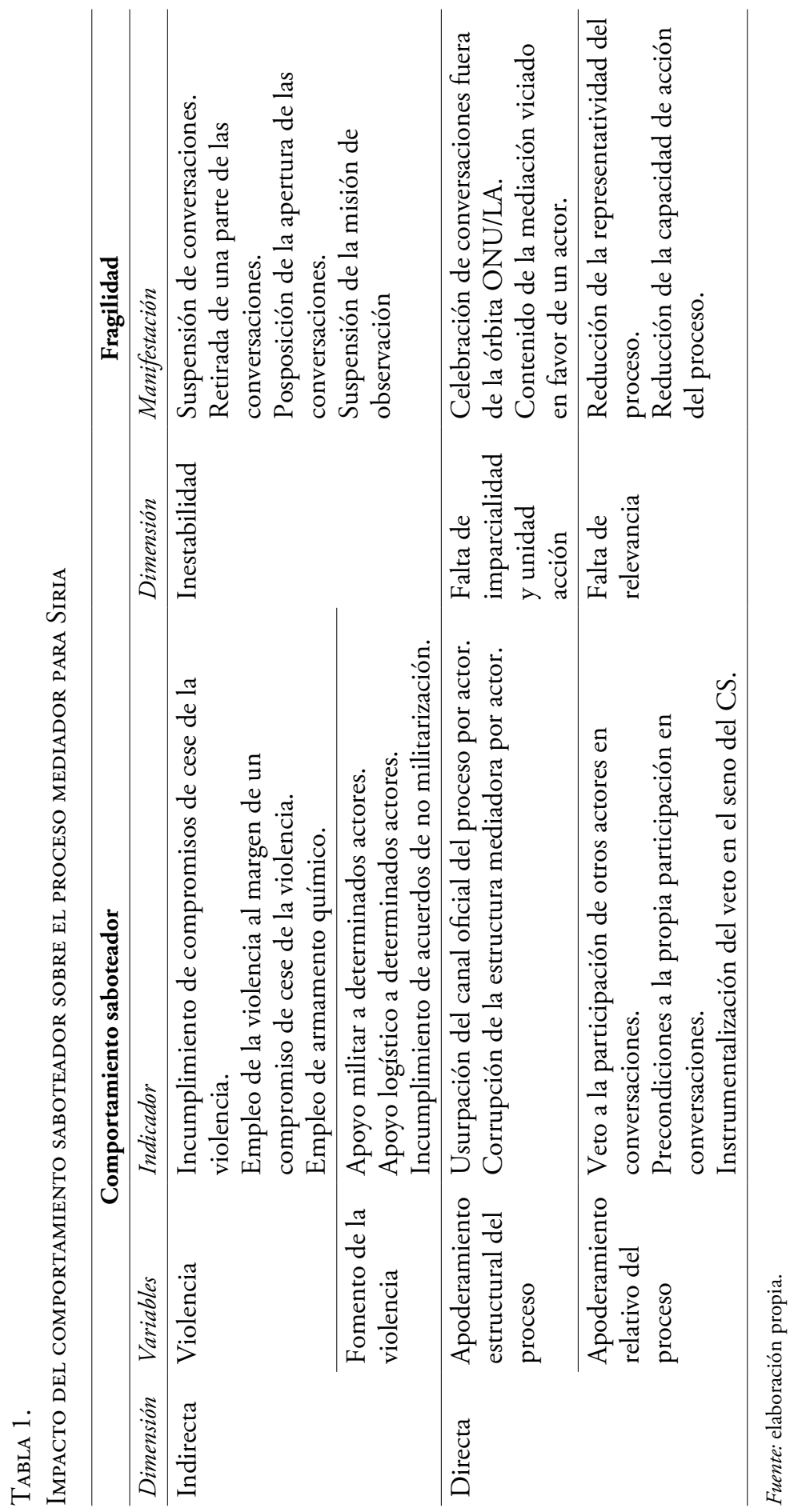




\section{EL IMPACTO DEL COMPORTAMIENTO SABOTEADOR SOBRE EL PROCESO MEDIADOR PARA SIRIA}

\section{El proceso de la Liga Árabe: la mediación de Al-Arabi}

El proceso mediador de la LA para Siria comenzó en agosto de 2011, cuando el entonces secretario general Al-Arabi llevó a cabo una serie de reuniones con el Gobierno sirio a fin de conseguir un compromiso de cese de la violencia y de apertura de conversaciones con la oposición. Dos meses después el régimen sirio aceptó comprometerse proforma con el primer Plan de Acción Ârabe (PAA) para Siria, retirando sus tropas de ciudades y consintiendo un cese de hostilidades y a la apertura de un proceso de diálogo nacional. Con el objetivo de supervisar este plan, la LA logró desplegar una misión de observación para Siria, la primera de estas características en la historia de la organización. Sin embargo, esta misión abandonó el país tras apenas un mes, lo que sumado al rechazo íntegro por el régimen de un segundo plan de acción provocó la retirada de la LA del centro de la mediación para Siria.

El comportamiento spoiling adoptado por las partes contra estos primeros pasos en la mediación se manifestó desde el inicio. En lo referente al sabotaje indirecto, la violencia propiciada por la incompatibilidad régimen-oposición desvirtuó rápidamente el compromiso contenido en el PAA al tomar protagonismo durante toda esta mediación, mientras que el apoyo logístico provisto por actores regionales e internacionales fomentó la violencia en el país, contribuyendo a los actos de sabotaje violentos por las partes internas.

Del lado del régimen, Rusia e Irán incrementaron sustancialmente sus exportaciones armamentísticas a Siria a lo largo del año 2011 en relación con 2009 y 2010 según datos del SIPRI. Del lado de la oposición, los EE. UU. rechazaron en principio la idea de proveer ayuda letal a los grupos rebeldes armados por miedo a que cayesen en manos equivocadas, mientras que el embargo de armas a Siria impuesto por la UE en 2011 redujo considerablemente las posibilidades de apoyo logístico por el plano internacional a la oposición (Wezeman, 2013). Sin embargo, en el nivel regional, a pesar de que ningún Gobierno de la zona admitió abiertamente estar proporcionando armas a los rebeldes sirios, existen informes que apuntan a la presencia en el país de armamento turco y de los países del Consejo de Cooperación del Golfo (CCG) que, a través de Jordania, Turquía y, más tarde, Irak, habrían habilitado un incipiente pasillo de aprovisionamiento de armas a la oposición (Asseburg et al., 2018).

El impacto de este comportamiento saboteador indirecto de fomento de la violencia por actores regionales e internacionales y de empleo de la violencia por las partes internas fraguó en una mediación frágil, marcada por la inestabilidad. La primera manifestación de esta inestabilidad fue la suspensión de la Misión de Observación apenas unas semanas después de su despliegue. El informe del jefe de la Misión de Observación de la LA adjunto en la carta de 24 de enero de 2012 dirigida al presidente del CS relata distintos episodios de violencia en varias urbes del país, protagonizados tanto por fuerzas gubernamentales como por rebeldes armados, varios 
intentos deliberados del Gobierno de limitar la capacidad de los observadores de la Misión y una serie de ataques perpetrados por «elementos leales al Gobierno» contra los propios observadores (ONU, 2012a). Este comportamiento saboteador llevó a la LA a suspender definitivamente la Misión. Al-Arabi afirmaba a este respecto que «dado el deterioro crítico de la situación en Siria y el continúo empleo de la violencia [...] se ha decidido cesar la actividad de la Misión» ${ }^{1}$.

La segunda manifestación de inestabilidad fue la imposibilidad de celebrar conversaciones de paz según estas habían sido programadas. Un objetivo primario de la estrategia de la LA tras la aceptación por las partes del PAA era la celebración de una convención nacional que reuniese a las partes una vez transcurridas dos semanas desde la aprobación por el Gobierno sirio (Syrian National Council, 2020). Sin embargo, la progresiva militarización del conflicto obligó a su posposición hasta, finalmente, impedir su celebración. Al-Arabi señaló al efecto que el derramamiento de sangre tendría que parar antes de que las negociaciones pudieran empezar ${ }^{2}$.

Por otro lado, el comportamiento spoiling directo, aunque más sutil en su impacto, también estuvo presente. En octubre de 2011, Francia, Alemania, Portugal y RU llevaron un borrador de resolución al CS que apoyaba los esfuerzos de la LA, dotándolos del respaldo de ONU. Sin embargo, el veto ruso y chino, escudándose en la narrativa del principio de no injerencia y el respecto a la soberanía siria, impidió ver la luz a esta resolución. Este apoderamiento relativo del proceso no solo hace evidentes las incompatibilidades que emergían entre las agendas occidentales, rusa y china, sino que además minaba los incipientes esfuerzos de paz, privando a la LA de la mayor capacidad de acción que hubiera podido proveer este pronto respaldo normativo de ONU.

Tras el fracaso de la misión de la LA, los Gobiernos del Golfo adoptaron una posición más radical y presionaron a la organización para enunciar un segundo plan más controvertido que exigía directamente la salida de Asad. El entonces ministro de Asuntos Exteriores catarí, Sheikh Hamad al-Thani, llegó a señalar en la enunciación del plan "pedimos que el régimen sirio se vaya y entregue el poder» ${ }^{3}$. El comportamiento adoptado por los países del CCG y, especialmente Arabia Saudí y Catar, es indicativo de un apoderamiento estructural que debilita el proceso en tanto ataca la propia estructura mediadora. Este ataque amenaza la imparcialidad de la mediación, desequilibrándola hacia el lado de la oposición, e instrumentaliza el proceso al alterar el mandato oficial del mediador sobre la base de las agendas de estos Estados.

La Guia para una mediación efectiva proporcionada por la ONU otorga especial importancia a la imparcialidad del mediador, pues de ser percibido como parcial

1. BBC. 2012. «Arab League suspends Syria mission. Nabil el-Arabi» BBC, 28-1-2012. Disponible en: https:/www.bbc.com/news/world-middle-east-16774171 [consulta: 29-12-2019].

2. Sly, Liz. 2012. «Arab League calls on Syria's Assad to step down», The Washington Post, 22-12012. Disponible en: t.ly/kvrVD [consulta: 2-1-2020].

3. Saleh, Yasmine y Lin Noueihed. 2012. "Arab League proposes new plan for Syrian transition», Reuters, 22-1-2012. Disponible en: t.ly/B95R7 [consulta: 2-1-2020]. 
arruinará sus posibilidades de progresar en la resolución del conflicto (ONU, 2012i). La mediación de Al-Arabi experimentó esta lógica. Con un primer mandato en 2011 (PAA) que consiguió proforma el compromiso del régimen, su modificación en 2012 por las injerencias de los Estados del CCG en este segundo plan corrompió la imparcialidad del mediador y provocó una reacción de rechazo y desconfianza del Gobierno sirio hacia el propio proceso. Frente a esto, la LA dio entrada finalmente a la ONU.

TABLA 2.

Comportamiento SABOteAdor en el PROCESO MEDIAdor para Siria De Liga Árabe

\begin{tabular}{|c|c|c|c|}
\hline Estrategia & Acto & Actor saboteador & Manifestación \\
\hline Violencia & $\begin{array}{l}\text { Incumplimiento } \\
\text { del PAA }\end{array}$ & $\begin{array}{l}\text { Régimen de Bashar al-Asad, } \\
\text { elementos de la incipiente } \\
\text { oposición armada }\end{array}$ & \multirow{2}{*}{$\begin{array}{c}\text { Posposición de la } \\
\text { apertura de las } \\
\text { conversaciones. } \\
\text { Suspensión de } \\
\text { la misión de } \\
\text { observación }\end{array}$} \\
\hline $\begin{array}{l}\text { Fomento de la } \\
\text { violencia }\end{array}$ & $\begin{array}{l}\text { Apoyo logístico- } \\
\text { armamentístico }\end{array}$ & $\begin{array}{c}\text { Rusia e Irán (régimen) } \\
\text { Turquía y CCG (oposición) }\end{array}$ & \\
\hline $\begin{array}{l}\text { Apoderamiento } \\
\text { estructural }\end{array}$ & $\begin{array}{c}\text { Corrupción de la } \\
\text { estructura mediadora }\end{array}$ & $\begin{array}{c}\text { Países del Golfo (Arabia } \\
\text { Saudí y Catar) }\end{array}$ & $\begin{array}{l}\text { Contenido de la } \\
\text { mediación viciado }\end{array}$ \\
\hline $\begin{array}{l}\text { Apoderamiento } \\
\text { relativo }\end{array}$ & $\begin{array}{l}\text { Instrumentalización } \\
\text { del veto en el CS }\end{array}$ & Rusia y China & $\begin{array}{c}\text { Reducción de la } \\
\text { capacidad de acción }\end{array}$ \\
\hline
\end{tabular}

Fuente: elaboración propia.

\section{El proceso mediador de la ONU: Kofi Annan}

Al inicio de su mandato, Annan trabajó para la consecución del conocido como Plan de Seis Puntos (6PP), una hoja de ruta sobre la que propiciar la apertura de un proceso político inclusivo y la consecución de un cese sostenido de la violencia. Para ello, Annan reclamó al Gobierno sirio que detuviese todos los movimientos de tropas hacia los centros de población, cesara el empleo de armas pesadas y retirase las concentraciones militares de las zonas residenciales (ONU, 2012b). Tanto régimen como oposición acataron el cumplimiento del Plan, que apoyado por el CS mediante la Resolución 2042 (2012) de 14 abril, redujo considerablemente los niveles de violencia durante unas semanas (Hinnebusch et al., 2016), permitiendo el despliegue de una segunda misión de observación, la Misión de Supervisión de ONU en Siria (UNSMIS) (ONU, 2012c).

Con estos limitados logros, Annan buscó el apoyo internacional y regional para avanzar en su hoja de ruta, convocando en junio al Grupo de Acción para Siria en las primeras conversaciones oficiales del país. Ginebra I reunió a dos de los niveles implicados en el conflicto: el internacional, con Francia, RU, EE.UU., Rusia y Unión Europea; y el regional, con Kuwait, Catar, Iraq, como representantes de la LA, y Turquía. El resultado, el Comunicado de Ginebra, cuyo contenido preveía entre otras 
cuestiones el cese de la violencia, una transición política y un calendario para la redacción de una nueva Constitución y la convocatoria de elecciones (Álvarez-Ossorio, 2016), ha permanecido inalterado a lo largo del proceso, a pesar de las marcadas diferencias que impone el plano bélico en la distribución del poder entre las partes y, aún en la actualidad, constituye la base del mandato oficial del mediador.

Aun consiguiendo esta inicial reducción de la violencia y la celebración de Ginebra I, distintas estrategias de sabotaje fueron empleadas por los actores implicados contra los esfuerzos de Annan. Por una parte, a pesar de acordar un cese de la violencia, los asaltos por el Gobierno y las respuestas cada vez más violentas de la oposición se intensificaron tras unas pocas semanas y desvirtuaron por completo el cese de hostilidades programado por el 6PP (ONU, 2012d).

Al mismo tiempo, el fomento a la violencia a través del apoyo logístico a los aliados internos no cejó. Rusia e Irán continuaron su flujo armamentístico hacia Siria mientras que, de forma poco esclarecida, la miríada de aliados regionales de la oposición, lideradas por Catar y Arabia Saudí, mantenía su provisión logística a los rebeldes (Asseburg et al., 2018). Este fomento de la violencia no le era desconocido al secretario general, que en su Informe sobre la aplicación de la Resolución 2043 (2012) (ONU, 2012d) insistía en el "compromiso de no militarización que el Grupo de Acción para Siria había convenido en el Comunicado de Ginebra, haciendo un «llamamiento a las terceras partes y, sobre todo, a los países de la región [...] a hacer todo lo que estuviese en su mano para poner fin a esta situación [de continua militarización]» (ONU, 2012e).

El impacto debilitador de estos comportamientos de sabotaje indirectos sobre la mediación de Annan se manifestó a finales de mayo, cuando oposición y régimen impidieron el desarrollo de la labor de la UNSMIS mediante ataques selectivos, disparos directos y bombardeos a patrullas de la Misión (ONU, 2012d). En consecuencia, el incumplimiento del 6PP por régimen y oposición, y del acuerdo de no militarización por actores regionales e internacionales, provocó la retirada de la UNSMIS, suspendida finalmente en agosto de 2012 (ONU, 2012f). Asimismo, estos actos de spoiling condenaron la apertura de conversaciones intrasirias, que se vieron pospuestas por la imposibilidad de crear un espacio político de confianza según los objetivos del mediador (ONU, 2012d). Esto demuestra cómo el fomento de la violencia y su empleo por las partes, ignorando los compromisos acatados, acabaron desestabilizando el proceso mediador.

Por otra parte, el comportamiento de sabotaje directo también estuvo presente porque Ginebra I se celebró con dos importantes ausencias del nivel regional. De un lado, la participación de Irán fue vetada por EE. UU. a pesar de las presiones de la ONU. De otro, la contraparte regional iraní, Arabia Saudí, tampoco fue invitada al proceso por las presiones impuestas por Rusia como quid pro quo por la exclusión de Irán (Lund, 2013). Esta instrumentalización del proceso demuestra un acto de apoderamiento relativo por EE.UU. y Rusia, que sabotean sutilmente la finalidad del proceso. Empleando su cuota de poder, ambos actores atacan la representatividad del proceso al exigir la exclusión de determinados actores de las conversaciones, aun cuando estos resultan ineludibles para encontrar una solución política al conflicto. 
En julio de 2012, el CS discutió la aprobación de una resolución que finalmente fue vetada por Rusia y China. En ella, se acogía el Comunicado de Ginebra, reforzándolo normativamente, se señalaba que la situación en Siria constituía una amenaza para la paz y seguridad internacionales y se decidía que, si el Gobierno sirio no cumplía sus obligaciones de cese de la violencia, se activarían inmediatamente medidas del art. 41 del capítulo VII de la Carta de la ONU (ONU, 2012g). La invocación de este artículo, aun excluyendo el uso de la fuerza, alertó inmediatamente a Rusia y China, que ejercieron su veto rechazando la imposición de sanciones contra el régimen (id.). Como resultado, estas potencias no solo blindaban al Gobierno sirio, sino que diluían la exigencia del Comunicado de Ginebra y restaban poder y capacidad de acción a la mediación de Annan, debilitando el proceso. "Una de mis mayores desilusiones [...] fue el 19 de julio — -señaló Annan-después de una reunión difícil pero constructiva [Ginebra I], en la que se acordó un comunicado, [...] el CS actuó y Rusia y China lo vetaron» (Zartman, 2019: 9).

TABLA 3.

Comportamiento Saboteador durante el mandato de Kofi AnNan

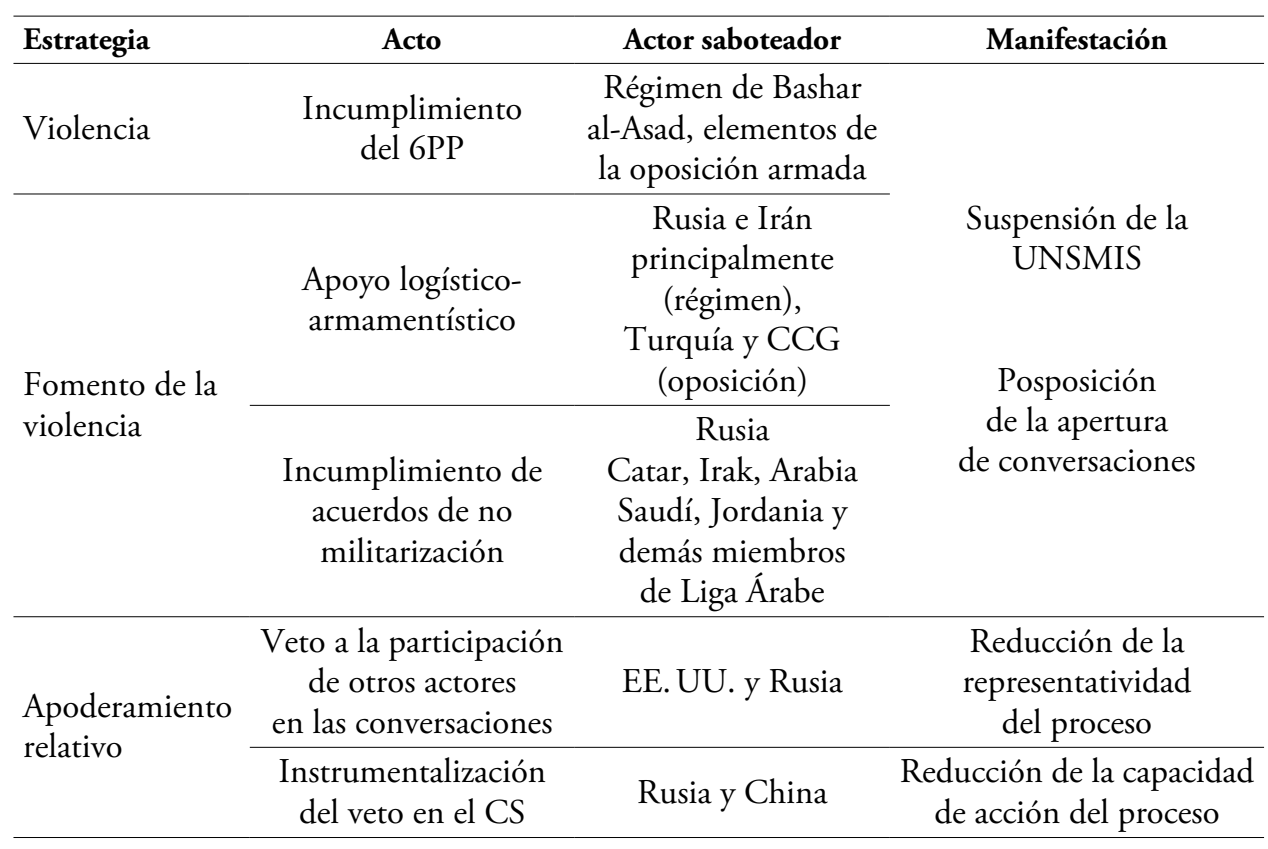

Fuente: elaboración propia.

El proceso mediador de la ONU: Lakhdar Brahimi

Brahimi asumió el cargo en septiembre de 2012. Al inicio, en paralelo con múltiples reuniones con actores regionales e internacionales a fin de conseguir sus apoyos 
para realzar el proceso (Hinnebusch et al., 2016), el enviado inauguró su mandato consiguiendo el compromiso tanto del régimen como de gran parte de la oposición con un cese de la violencia entre los días 26 y 30 de octubre con motivo de la celebración del Eid al-Adha ${ }^{4}$, pero su cumplimiento solo duró cinco horas (ONU, 2012h). A partir de la confianza que podría haber generado este alto al fuego, Brahimi esperaba poder convocar Ginebra II: «Si esta humilde iniciativa tiene éxito, espero que podamos seguir construyendo sobre ella a fin de lograr un cese al fuego más sostenido, parte de un proceso político comprehensivo" ${ }^{5}$. Sin embargo, el incumplimiento por las partes internas de este instrumento de cese a la violencia, sumado a los primeros ataques químicos lanzados por el régimen, complicaron las perspectivas de abrir este espacio político. Solo entre enero de 2013 y mayo de 2014 se contabilizaron entre cuarenta y setenta ataques químicos en distintos puntos del país, según se acuda a una u otra fuente (Syrian Archive, 2019; Schneider y Lütkefend, 2019).

Estos actos violentos tuvieron un impacto particularmente desestabilizador del proceso. Ginebra II, en mente de Brahimi desde su inicio en el cargo, parecía empezar a cobrar fuerza después del golpe del incumplimiento del acuerdo del Eid al-Adha, especialmente a partir de la reunión ruso-estadounidense en Moscú en mayo de 2013. Sin embargo, «ahora se [encontraba] en grave peligro tras los eventos del 21 de agosto [ataque químico de Guta] y las reacciones que [podrían seguir] como consecuencia» (ONU, 2013). Así, el impacto de estos actos de sabotaje violentos debilitó la mediación de Brahimi, obligando a la posposición de la apertura de las primeras conversaciones intrasirias en tres años de conflicto, que tuvieron que esperar finalmente hasta enero de 2014.

Los actos de fomento de la violencia por los actores regionales e internacionales durante este período se mantuvieron y contribuyeron a la desestabilización del proceso de una forma que no pasó desapercibida. El flujo armamentístico, económico y de asesoramiento a régimen y oposición por sus respectivos aliados «daña [ba] las perspectivas de un proceso político» (ONU, 2014). Del lado de la oposición, aparecían las primeras evidencias de suministro armamentístico estadounidense a los rebeldes y se levantaba el embargo europeo, abriendo una posibilidad que Francia y RU aprovecharon para enviar ayuda letal a los rebeldes sirios (Asseburg et al., 2018). Estos apoyos violaron flagrantemente el acuerdo de no militarización contenido en el Comunicado de Ginebra (parágrafo 12, «medidas convenidas») que, incorporado al corpus normativo de la ONU por la Resolución 2118 del CS, era exigible ahora a toda la comunidad internacional.

La reacción internacional de alarma producida por los ataques químicos en Guta sirvió a Brahimi a finales de 2013 para recabar el impulso del CS en la reapertura de Ginebra, y consiguió finalmente su convocatoria entre enero y febrero de 2014. Sin embargo, en el diseño de la conferencia los actos spoiling de apoderamiento relativo de algunas potencias

4. BBC. 2012. «Syria government 'agrees to Eid al-Adha ceasefire'» $B B C, 24$ de octubre. Disponible en: https://www.bbc.com/news/world-middle-east-20066613 [Consulta de 3 de enero de 2020]

5. Saleh, Yasmine, Shaimaa Fayed. 2012. «Syria agrees to ceasefire during Eid holiday: Brahimi». Reuters, 24 de octubre. Disponible en: t.ly/GxeJr [Consulta: 18 de enero de 2020] 
y de la oposición afectaron a la representatividad de las conversaciones, debilitando la mediación de Brahimi. Los vetos de EE. UU. a la inclusión de Irán (Lund, 2013), y de Turquía a la del grupo kurdo del PYD 6 , excluyeron del proceso a actores indispensables en cualquier esfuerzo de solución real del conflicto. Estos comportamientos demuestran una motivación de instrumentalización del proceso para garantizar la imposición de una agenda nacional en Ginebra para hallar una solución comprehensiva al conflicto.

TABLA 4.

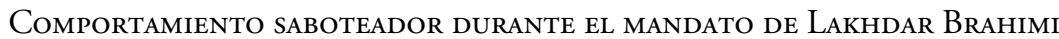

\begin{tabular}{|c|c|c|c|}
\hline Estrategia & Acto & Actor saboteador & Manifestación \\
\hline \multirow{2}{*}{ Violencia } & $\begin{array}{l}\text { Incumplimiento } \\
\text { del Eid Al-Adha }\end{array}$ & $\begin{array}{l}\text { Régimen, elementos de la } \\
\text { oposición armada }\end{array}$ & \multirow{5}{*}{$\begin{array}{l}\text { Posposición de la } \\
\text { apertura de } \\
\text { conversaciones }\end{array}$} \\
\hline & $\begin{array}{c}\text { Empleo de } \\
\text { armamento químico }\end{array}$ & Régimen & \\
\hline \multirow{3}{*}{$\begin{array}{l}\text { Fomento de la } \\
\text { violencia }\end{array}$} & $\begin{array}{l}\text { Apoyo logístico- } \\
\text { armamentístico }\end{array}$ & $\begin{array}{c}\text { Rusia, Irán y proxies } \\
\text { principalmente (régimen) } \\
\text { CCG, Turquía, Francia, RU y } \\
\text { EE. UU. (oposición) }\end{array}$ & \\
\hline & Apoyo militar & Irán (régimen) & \\
\hline & $\begin{array}{l}\text { Incumplimiento de } \\
\text { acuerdos de no } \\
\text { militarización }\end{array}$ & $\begin{array}{l}\text { Rusia, EE. UU., Francia, RU } \\
\text { Catar, Arabia Saudí, Irak, } \\
\text { Jordania, demás miembros de } \\
\text { LA y Turquía }\end{array}$ & \\
\hline \multirow{2}{*}{$\begin{array}{l}\text { Apoderamiento } \\
\text { relativo }\end{array}$} & $\begin{array}{c}\text { Veto a la participación } \\
\text { de otros actores en las } \\
\text { conversaciones }\end{array}$ & EE. UU. y Turquía & \multirow{2}{*}{$\begin{array}{l}\text { Reducción de la } \\
\text { representatividad } \\
\text { del proceso }\end{array}$} \\
\hline & $\begin{array}{l}\text { Precondiciones a la } \\
\text { propia participación }\end{array}$ & Oposición siria & \\
\hline
\end{tabular}

Fuente: elaboración propia.

Del lado de la oposición, la imposición de precondiciones a su participación también amenazó la representatividad de Ginebra. La delegación opositora mimetiza la fragmentación que caracteriza a los rebeldes sobre el plano bélico, de forma que, aunque entonces liderada por la Coalición Nacional, varios de sus integrantes mantuvieron una línea más dura, llegando a amenazar la representatividad de las conversaciones mediante la imposición de la salida de Bashar al-Asad como precondición para su asistencia ${ }^{7}$. De forma similar al comportamiento anterior, este acto de apoderamiento relativo, esta vez

6. Zaman, Amberin. 2013. «Syrian Kurds jockey for seat at Geneva talks». Al-Monitor, 16-122013. Disponible en: t.ly/625pB [consulta: 16-1-2020].

7. Black, Ian. 2013. «Friends of Syria talks begin as doubt hangs over Geneva II peace conference». The Guardian, 6-6-2013. Disponible en: t.ly/1kqGL [consulta: 16-1-2020]. 
por actores que amenazaban con autoexcluirse, instrumentaliza el proceso imponiendo ex ante una agenda propia sobre la base de "peticiones irreales» (Reiter, 2016) al pretender obtener de ella lo que el actor es incapaz de obtener por sí mismo, ya sea sobre el terreno o sobre la mesa de negociación.

\section{El proceso mediador de la ONU: Staffan de Mistura}

El año 2015 estuvo marcado por profundos cambios en el plano bélico. La entrada en escena del autodenominado Estado Islámico (EI), la activación de la coalición internacional contra el EI y el inicio de la intervención militar rusa en septiembre modificó de forma determinante el territorio controlado por cada uno de los beligerantes. Esto disparó las acciones diplomáticas en el nivel internacional, que reunió a potencias detractoras y partidarias del régimen en Viena, incluyendo por primera vez a Irán. El resultado, las Declaraciones de Viena, fue refrendado por el CS en la famosa Resolución 2254 (2015), cuyo contenido insiste en los principales elementos del Comunicado de Ginebra.

Aprovechando el impulso de Viena, De Mistura, recién nombrado enviado el año anterior, consiguió convocar a las partes en Ginebra por primera vez después de dos años. No obstante, Ginebra III, desarrollada en dos rondas entre enero y abril de 2016, sufrió con especial incidencia el impacto debilitante de los actos de sabotaje indirectos. Justo a su inicio, el régimen protagonizó una fuerte ofensiva sobre Alepo que provocó la retirada de la oposición en señal de repulsa y obligó a la suspensión de las negociaciones ${ }^{8}$. A su cierre, De Mistura señaló que «cada vez que hay una oportunidad de negociación, ocurre justo lo contrario sobre el terreno, [las partes] incrementan los ataques» ${ }^{9}$. Estos actos de empleo de la violencia llevados a cabo por las partes internas y sus aliados internacionales y regionales sobre el terreno desestabilizaron el proceso, generando un clima de desconfianza que provocó la retirada de la oposición y puso fin bruscamente a esta primera ronda de conversaciones.

Ante esto, como medida para generar confianza, Rusia, EE. UU., régimen y parte de la oposición acordaron a mediados de febrero en Múnich un cese de hostilidades. Este acuerdo fue refrendado por el CS en la Resolución 2268 (2016), que además requería de todos los Estados miembros «crear las condiciones para un alto al fuego duradero», cortando todo flujo armamentístico a fin de garantizar así el cumplimiento del acuerdo y propiciar la reanudación de las conversaciones. En el marco creado por esta iniciativa, De Mistura consiguió reunir de nuevo a las partes en Ginebra III entre marzo y abril, pero el aumento deliberado de las hostilidades por las partes no solo

8. Black, Ian y Patrick Wintour. 2016. «Suspended Syrian peace talks to resume in Geneva next week». The Guardian, 1-3-2016. Disponible en: t.ly/drPDL [consulta: 28-11-2019].

9. Sinjab, Lina. 2016. «Syria conflict: Who's to blame for talks suspension?». BBC, 4-2-2016 Disponible en: https://www.bbc.com/news/world-middle-east-35490273 [consulta: 3-1-2020]. 
arruinó el recién acuerdo de Múnich, sino que de nuevo desestabilizó el proceso, provocando la suspensión definitiva de Ginebra III y la retirada de la oposición (The Carter Center, 2016). En el momento de la suspensión, De Mistura aclaró el impacto de este comportamiento: "[La retirada de la oposición] se debió a su disgusto y preocupación con la degradación de la situación humanitaria y los problemas relativos al cese de hostilidades» ${ }^{10}$.

El impacto del comportamiento de sabotaje indirecto sobre las conversaciones fue referido en varias ocasiones por el entonces enviado especial durante la entrevista realizada por la autora. De Mistura señaló que "cuando se producía un acercamiento internacional, algún entendimiento ruso-estadounidense, y claramente había esperanza en el proceso [...] tanto Gobierno como oposición actuaban como verdaderos spoilers [...] provocando incidentes o iniciando ataques y demás para minar el proceso». Este tipo de comportamiento spoiling indirecto empleado por las partes internas y sus aliados, y apoyado por actores regionales e internacionales mediante el mantenimiento del flujo armamentístico (vid. supra) a pesar de sus obligaciones respecto a la Resolución 2268 (2016) y anteriores, desestabilizó el proceso mediante la suspensión abrupta de las conversaciones, arruinando así cualquier iniciativa favorable a la generación de un clima de confianza.

El comportamiento spoiling directo, siempre más sutil, también impactó en Ginebra III. En su entrevista, De Mistura señalaba que «la influencia del Gobierno turco sobre la oposición le permitía frenar cualquier participación del PYD [...] pues, de no ser así, [Turquía] habría bloqueado todo [el proceso]». El mantenimiento del veto turco a la organización política kurda supone otra vez el empleo por Turquía de su cuota de poder sobre el proceso para la definición de sus participantes aún en detrimento de su representatividad y, por ende, de las posibilidades de encontrar una solución al conflicto comprehensiva e inclusiva de actores ineludibles.

En esta misma línea, la delegación opositora planteó distintas precondiciones a su participación centradas en la exigencia de la salida de Asad. De hecho, en sus declaraciones a la apertura de esta ronda, De Mistura se mostraba preparado: «Los spoilers procurarán alterar las conversaciones [...] y su retórica pública intentará imponer precondiciones $[\ldots] »^{11}$. La oposición volvió a abusar del poder que le otorga su presencia imprescindible en el proceso exigiendo «peticiones irreales» (vid. supra) que trasladan el peso de la negociación al mediador y amenazan la representatividad de las conversaciones, debilitando la relevancia del proceso.

A finales de 2016 comenzó a fraguarse el proceso de Astaná. En los años venideros, Rusia, Turquía e Irán, que se autonombraron «Estados guardianes», celebraron varias rondas negociadoras en las que adoptaban una suerte de posición mediadora entre el

10. Hudson, John. 2016. "Syrian Opposition Suspends Peace Talks Amid Anti-Assad Offensive», Foreign Policy. Disponible en: t.ly/DGKO2 [consulta: 24-12-2019].

11. Wintour, Patrick. 2016. «UN's Syria envoy warns of attempts to derail peace talks» The Guardian, 14-3-2016. Disponible en: t.ly/1kqYL [consulta: 4-1-2020]. 
régimen y la oposición tolerada, mientras Ginebra veía debilitada su unidad de acción, por lo que redujo considerablemente el número de conferencias celebradas en relación con Astaná.

La apertura de esta vía supone un apoderamiento estructural del proceso. La Guía para una mediación efectiva propuesta por ONU como marco de referencia, señala que «el mediador tiene que ser capaz de ofrecer un proceso equilibrado que trate a todos los actores equitativamente y no debe tener un interés material en el resultado [del proceso]» (ONU, 2012i:10). Desde una óptica interna al propio proceso de Astaná, estos Estados garantes no están en condiciones de proporcionar la imparcialidad que ha de predicarse de toda estructura mediadora, por cuanto que son parte del propio conflicto y mantienen efectivamente una agenda propia que imprimen en el proceso. De hecho, estos tres guardianes han empleado Astaná para producir su propia versión de la paz coherente con sus agendas. En consecuencia, los resultados más tangibles de este proceso, el acuerdo de desmilitarización de cuatro zonas en Siria en 2017 y la redirección de los esfuerzos del proceso desde la transición política hacia la mera reforma constitucional dando por sentada la permanencia de Asad, hayan favorecido los intereses de estas potencias (Hinnebusch e Imady, 2017).

Desde una óptica externa, Rusia, Turquía e Irán han creado un proceso que, en lugar de servir a los fines de Ginebra, compite con ella, reduciendo su protagonismo y unidad de acción. Aunque De Mistura procuró mantener una posición pragmática que utilizase Astaná para favorecer Ginebra — «los esfuerzos de Astaná deben observarse como base para una renovada Ginebra» (Consejo de Seguridad, 2017)_, Rabbani, exconsejero del enviado, era especialmente contundente señalando «no creo que [De Mistura] se estuviese dando cuenta de que estaba básicamente bendiciendo su propia irrelevancia ${ }^{12}$. Desde la ONU se expresaba preocupación, por cuanto la creación de Astaná por los tres guardianes podría producir «problemas de coordinación» (Lundgren, 2019:10) que, efectivamente, terminaron debilitando Ginebra, alejando el canal diplomático oficial de la órbita de la organización.

Un año después, entre febrero y marzo de 2017, en la antesala del avance de Asad sobre el terreno, De Mistura consiguió reavivar el proceso tras la aceptación por las partes a participar en las conversaciones de Ginebra IV y V. Estas conversaciones, aunque sin progreso sustantivo, siguieron cierto ritmo natural, produciendo una agenda y la aceptación de unos puntos comunes preparados por el mediador (ONU, 2017b; ONU, 2017c). A pesar de la presencia de actos de violencia, estos no tuvieron el potencial suficiente para interrumpir las conversaciones, De Mistura era consciente de ello: «Suponemos siempre [...] que los spoilers intentan influenciar las conversaciones. Es del interés de las partes $[\ldots]$ no permitírselo» ${ }^{13}$. No obstante, el comportamiento spoiling

12. Kenner, David. 2018. «Even a 'Diplomat's Diplomat' Can't Solve Syria's Civil War». The Atlantic, 26-11-2018. Disponible en: t.ly/ZL2rE [consulta: 10-1-2020].

13. Irish, John, Stephanie Nebehay y Tom Miles. 2017. «Bombings, air strikes in Syria rattle Geneva peace talks». Reuters, 25-2-2017. Disponible en: t.ly/XOGeO [consulta: 30-11-2019]. 
directo sí mantuvo su impacto debilitador sobre la relevancia del proceso. Los actos de apoderamiento relativo, de nuevo el veto turco al PYD y el establecimiento de precondiciones, tanto por la oposición como por el régimen (ONU, 2017a), atacaron la mediación de De Mistura sobre la base de su representatividad.

A mediados de año, el Gobierno sirio mejoró decisivamente su posición al extenderse aproximadamente por la mitad del territorio. Frente a este renovado juego de fuerzas, De Mistura optó por primar una estrategia basada en reuniones políticas más informales y de menor duración, de forma que Ginebra VI, en mayo, y Ginebra VII, en julio, aunque de nuevo sin presencia del PYD por el veto turco, oscilaron entre los cuatro y cinco días de conversación con el propósito, según el enviado especial, de «dejar menos tiempo a la retórica pública» de las partes ${ }^{14}$, minimizando el impacto de sus precondiciones sobre el proceso. Además, a pesar de que «estas conversaciones se celebraron bajo la sombra de una intensificación de la violencia» (ONU, 2017d), el nuevo balance de fuerzas imperante en el plano bélico previno a la oposición de retirarse de las conversaciones, por lo que estos actos de sabotaje indirectos no tuvieron, como en el pasado, el impacto de desestabilizar las conversaciones que, en palabras del enviado, se celebraron «sin ofrecer avances, pero tampoco rupturas significativas» (Escola de Cultura de Pau, 2018).

El final de 2017 vio un giro sustancial en la agenda política del proceso en Ginebra. De Mistura comenzó a primar una agenda centrada en el proceso constitucional y la programación de unas elecciones supervisadas por la ONU, reduciendo significativamente el ambicioso contenido político del Comunicado de Ginebra. Sobre esta nueva base, De Mistura consiguió que las partes se volvieran a reunir en Ginebra VIII, pero el comportamiento saboteador del régimen debilitó especialmente esta iniciativa. En una renovada posición de fuerza, el Gobierno sirio acusó a la oposición de imponer precondiciones en una declaración, el manifiesto de Riad 2, que llamaba a la exclusión de Asad de todo proceso electoral. Con esta excusa, la delegación del régimen se retiró bruscamente de las conversaciones (Zartman, 2019: 17), de las que De Mistura señaló que "había sido una oportunidad de oro desperdiciada».

Aunque el enviado advirtió a la oposición en la redacción del manifiesto que este podría malinterpretarse, aclaró que «la delegación opositora no había planteado precondiciones y su [rechazo a Asad en unas hipotéticas elecciones] debía ser interpretado como una opinión, no como una precondición [a su participación en las conversaciones]» $\aleph^{15}$. Sin embargo, el enviado sí acusó al Gobierno de fijar precondiciones (Escola de Cultura de Pau, 2018) y, de esta forma, mermar la representatividad de Ginebra, imposibilitando la continuación de las conversaciones.

En el último período de la mediación de De Mistura, el enviado trabajó para atraer de nuevo el impulso necesario para celebrar conversaciones. Sin embargo, Ginebra vio

14. Albouy, Pierre. 2017. «Arranca en Ginebra una nueva ronda de las conversaciones de paz sobre Siria», Europa Press, 16-5-2017. Disponible en: t.ly/3dnzv [consulta: 2-1-2020].

15. Wintour, Patrick. 2017. "Golden opportunity lost as Syrian peace talks collapse». The Guardian, 14 de diciembre. Disponible en: t.ly/YByq0 [Consulta: 3 de enero de 2020] 
significativamente reducida su acción a raíz del fortalecimiento del proceso de Astaná. Durante el año 2018, Rusia, Turquía e Irán convocaron varias rondas de conversaciones mientras que Ginebra dejó formalmente de reunirse hasta finales de 2019, ya con un nuevo enviado. Esta merma de la unidad de acción de Ginebra, debido a la intensificación de los actos de apoderamiento estructural de los estados garantes de Astaná, pone de manifiesto la especial incidencia debilitante de este tipo de comportamiento sobre el proceso de Ginebra.

TABLA 5.

Comportamiento saboteador durante el mandato de Staffan de Mistura

\begin{tabular}{|c|c|c|c|c|}
\hline $\begin{array}{l}\text { Estrategia } \\
\text { spoiling }\end{array}$ & Acto & Actor saboteador & $\begin{array}{l}\text { Iniciativa } \\
\text { afectada }\end{array}$ & Manifestación \\
\hline Violencia & $\begin{array}{c}\text { Empleo de la } \\
\text { violencia con } \\
\text { anterioridad a la } \\
\text { Resolución } 2268 \\
\text { (2016). } \\
\text { Incumplimiento de } \\
\text { la Resolución } 2268 \\
\text { (2016)-Acuerdo de } \\
\text { Múnich }\end{array}$ & $\begin{array}{l}\text { Régimen, } \\
\text { oposición, } \\
\text { Rusia, Irán, } \\
\text { CCG, Turquía, } \\
\text { Francia, RU y } \\
\text { EE. UU. }\end{array}$ & \multirow[t]{2}{*}{ Ginebra III } & \multirow[t]{2}{*}{$\begin{array}{l}\text { Retirada de la } \\
\text { oposición. } \\
\text { Suspensión de las } \\
\text { negociaciones }\end{array}$} \\
\hline $\begin{array}{l}\text { Fomento de la } \\
\text { violencia }\end{array}$ & $\begin{array}{l}\text { Apoyo militar a } \\
\text { determinados } \\
\text { actores. } \\
\text { Apoyo logístico a } \\
\text { determinados } \\
\text { actores }\end{array}$ & $\begin{array}{c}\text { Rusia, Irán y } \\
\text { proxies (régimen) } \\
\text { CCG, Turquía, } \\
\text { Francia, RU y } \\
\text { EE. UU. } \\
\text { (oposición) }\end{array}$ & & \\
\hline $\begin{array}{l}\text { Apoderamiento } \\
\text { estructural }\end{array}$ & $\begin{array}{l}\text { Usurpación del } \\
\text { canal oficial del } \\
\text { proceso }\end{array}$ & $\begin{array}{l}\text { Rusia, Turquía } \\
\text { e Irán }\end{array}$ & $\begin{array}{c}\text { Conjunto del } \\
\text { proceso ONU a } \\
\text { partir de } 2017, \\
\text { con especial } \\
\text { énfasis en Viena }\end{array}$ & $\begin{array}{l}\text { Celebración de } \\
\text { conversaciones } \\
\text { fuera de la órbita } \\
\text { ONU }\end{array}$ \\
\hline \multirow[t]{2}{*}{$\begin{array}{l}\text { Apoderamiento } \\
\text { relativo }\end{array}$} & $\begin{array}{c}\text { Veto a la } \\
\text { participación kurda }\end{array}$ & Turquía & $\begin{array}{c}\text { Ginebra III } \\
\text { Ginebra IV } \\
\text { Ginebra V } \\
\text { Ginebra VI } \\
\text { Ginebra VII } \\
\text { Ginebra VIII }\end{array}$ & \multirow[t]{2}{*}{$\begin{array}{l}\text { Reducción de la } \\
\text { representatividad } \\
\text { del proceso }\end{array}$} \\
\hline & $\begin{array}{c}\text { Precondiciones a la } \\
\text { propia } \\
\text { participación }\end{array}$ & $\begin{array}{l}\text { Oposición y } \\
\text { régimen }\end{array}$ & $\begin{array}{c}\text { Ginebra III } \\
\text { Ginebra IV } \\
\text { Ginebra V } \\
\text { Ginebra VIII }\end{array}$ & \\
\hline
\end{tabular}

Fuente: elaboración propia. 


\section{El proceso mediador de la ONU: Geir Pedersen}

A la salida de De Mistura, el actual enviado especial Pedersen concentró sus esfuerzos durante 2019 en la tarea de formalizar un comité constitucional bajo el marco de Ginebra. En la órbita de los Estados guardianes de Astaná, ya un año antes tuvieron lugar en Sochi unas conversaciones en las que se propuso crear este órgano con una estructura que diese cabida a ciento cincuenta candidatos, de los que dos tercios estarían repartidos entre régimen y oposición, y uno entre miembros de la sociedad civil. Aunque impulsar un proceso de reforma constitucional no es novedad en Ginebra, cuyo mandato político lo ordenaba desde sus inicios, la idea de la Resolución 2254 (2015) del CS apuntaba más a encumbrar con una constitución reformada y refrendada por los sirios un proceso político más amplio (vid. supra), no a reducirlo a una mera revisión constitucional. Sin embargo, a fecha de febrero de 2020, el mandato del actual enviado enfrenta una fase del conflicto que permea especialmente el proceso de Ginebra y eleva la posición de fuerza de la delegación del régimen, haciendo especialmente difícil para el mediador ejercer su influencia para abarcar la totalidad de las cuestiones políticas propuestas en esta resolución.

En consecuencia, Pedersen trabajó en 2019 para conseguir un acuerdo sobre la composición y las reglas de procedimiento del Comité entre las delegaciones, y lo logró a finales de año. En septiembre, las partes pactaron el primer acuerdo político concreto en todo el proceso, los términos de referencia y reglamento del Comité, permitiendo su convocatoria un mes después (ONU, 2019).

A pesar de este primer impulso, esta reunión no fue fácil. Con un régimen reforzado, la intransigencia de su delegación aumentó y, al cierre de la primera ronda, Asad declaró que «la participación de una delegación del régimen en Ginebra no debe ser interpretada como un compromiso con Ginebra [...]» ${ }^{16}$. Su posición se endureció en la segunda ronda de forma que el régimen, con el fin de ralentizar el trabajo del Comité, optó de nuevo por amenazar la representatividad del proceso mediante la imposición de precondiciones a su presencia (Ortagus, 2019). Este acto de apoderamiento relativo, junto con el reiterado veto turco a la presencia en el Comité de las esencialmente kurdas Fuerzas Democráticas Sirias, debilitó de nuevo el proceso desde la perspectiva de su representatividad y atacó el resultado más tangible conseguido por Ginebra hasta el momento.

Al término de la segunda ronda en diciembre de 2019, Pedersen mantiene una postura optimista que busca nuevas formas de reunir otra vez a las partes. A pesar de ello, la pandemia mundial propiciada por la COVID-19 ha sido instrumentalizada por el régimen como pretexto para evitar reunir otra vez el Comité Constitucional, ralentizando aún más el proceso. Después de todo, el enviado es muy consciente de que este Comité no resuelve el conflicto, pero defiende que ofrece una puerta para

16. Seligman, Lara y Colum Lynch. 2019. "As Assad Gains Ground, New Syria Talks Offer Little Hope of Peace», Foreign Policy. Disponible en: t.ly/N6Yq8 [Consulta: 9 de enero de 2020]. 
mantener vivo un proceso político por el que traer a la mesa mayores cuestiones en el futuro (Harland y Khalifa, 2019).

TABLA 6.

Comportamiento saboteador durante el mandato de Geir Pedersen (hasta diciembre DE 2019)

\begin{tabular}{|c|c|c|c|}
\hline Estrategia & Acto & Actor saboteador & Manifestación \\
\hline $\begin{array}{l}\text { Apoderamiento } \\
\text { estructural }\end{array}$ & $\begin{array}{l}\text { Usurpación del canal } \\
\text { oficial del proceso }\end{array}$ & Rusia, Turquía e Irán & $\begin{array}{c}\text { Celebración de } \\
\text { conversaciones fuera } \\
\text { de la órbita ONU }\end{array}$ \\
\hline \multirow{2}{*}{$\begin{array}{l}\text { Apoderamiento } \\
\text { relativo }\end{array}$} & $\begin{array}{c}\text { Veto a la participación } \\
\text { kurda }\end{array}$ & Turquía & \multirow{2}{*}{$\begin{array}{l}\text { Reducción de la } \\
\text { representatividad } \\
\text { del proceso }\end{array}$} \\
\hline & $\begin{array}{l}\text { Precondiciones a la } \\
\text { propia participación }\end{array}$ & Régimen & \\
\hline
\end{tabular}

Fuente: elaboración propia.

\section{CONCLUSIONES}

La fragilidad del proceso de mediación para Siria guiado por la Liga Árabe y Naciones Unidas no solo se manifiesta en la incapacidad del proceso de producir resultados tangibles en la realidad siria, sino también en la inestabilidad de sus iniciativas, su falta de representatividad y capacidad de acción, y la falta de imparcialidad y unidad de acción de su estructura mediadora. Las causas de estos indicios de fragilidad hay que buscarlas en el comportamiento saboteador, adoptado por los actores implicados tanto dentro como fuera del proceso. Operacionalizando el concepto del spoiler, este artículo aborda los distintos actos que abarca este comportamiento y el tipo de impacto que tienen, explicando la relación entre estos y la fragilidad del proceso.

Para ello, el análisis ha distinguido entre dos grandes dimensiones del comportamiento saboteador: una indirecta, comprehensiva de los actos violentos o de fomento de la violencia que se producen en el terreno e impactan sobre el proceso desestabilizándolo, y una directa que tiene lugar en el plano diplomático y comprende actos que lo instrumentalizan, bien desafiando la imparcialidad y unidad de acción de la estructura mediadora mediante la injerencia en los objetivos de la mediación oficial o la creación de un proceso paralelo fuera del control de la ONU (apoderamiento estructural), o bien amenazando su representatividad y capacidad de acción mediante la modificación de aspectos clave del proceso oficial ONU a conveniencia de la agenda de distintos actores (apoderamiento relativo).

Las contribuciones al debate teórico del spoiler son fundamentalmente tres. Primero, el artículo hace más transparente el tipo de impacto que los diferentes comportamientos de sabotaje tienen sobre una mediación, alejando la aplicación del concepto de resultados deterministas que asocian al spoiler directamente con la dicotomía éxito-fracaso 
de un proceso y que obvian la variedad de mecanismos causales que activa la adopción de este tipo de comportamientos en el seno de un proceso. Segundo, la operacionalización que se ofrece examina el efecto que el comportamiento de sabotaje no violento tiene sobre un proceso, asentando el debate en torno a dos nuevos conceptos (el apoderamiento relativo y estructural) que captan tanto la forma que adopta este comportamiento como el impacto que produce. Tercero, esta operacionalización no solo presta atención al efecto del comportamiento de sabotaje sobre productos del proceso (fundamentalmente acuerdos de ceses de la violencia y hojas de ruta) sino que, al ampliar el análisis incluyendo actos spoiling no violentos, el artículo tiene en cuenta también el impacto del spoiler sobre el diseño del proceso y su estructura mediadora.

La aplicación de esta operacionalización demuestra el impacto debilitante de estos comportamientos sobre el proceso. Los actos de sabotaje de naturaleza violenta tienen especial incidencia en las primeras mediaciones y provocan reacciones más drásticas en las partes, dificultando la continuidad del proceso. Los actos constantes de apoyo a la violencia, como el aprovisionamiento logístico y militar por actores internacionales y regionales, y los actos violentos per se por las partes internas y sus aliados, desvirtúan los compromisos con el cese de la violencia adoptados (PAA, 6PP, el Comunicado de Ginebra, el acuerdo del Eid Al-Adha y el acuerdo de Múnich) y tienen un efecto desestabilizador sobre el proceso, por cuanto obligan a la interrupción brusca de sus iniciativas, ya sea la retirada de las misiones de observación en apoyo del mediador o en forma de suspensión y posposición de conversaciones de paz.

Las estrategias spoiling directas instrumentalizan el proceso de una forma sutil, pero no por ello menos relevante. El apoderamiento relativo funciona como una constante que amenaza la capacidad de acción del mediador y la representatividad de las iniciativas. Desde el comienzo del proceso, la instrumentalización del veto en el CS por Rusia y China ha restado en varias ocasiones el respaldo de este órgano a varios productos del plano diplomático, como el propio Comunicado de Ginebra en sus inicios, mientras que en el seno de las conversaciones en Ginebra, EE. UU., Rusia y Turquía han impuesto su veto en varias ocasiones a la participación de distintos actores ineludibles en la resolución del conflicto, atacando la representatividad del proceso.

Igualmente, la imposición de precondiciones a la propia participación ha sido un recurso ampliamente utilizado por las partes internas. En la mediación de Brahimi fue la oposición la que empleó esta estrategia, coincidiendo con una posición de fuerza en el terreno; mientras que, a partir de la mediación de De Mistura, ha sido empleada por el régimen en paralelo con su mejoría en el plano bélico. En cualquier caso, ambas posiciones demuestran una voluntad de instrumentalización del proceso, ya sea para utilizarlo como una estrategia de guerra más, para extraer recursos, tiempo, legitimación internacional o exigir objetivos que el actor se muestra incapaz de conseguir por sí mismo, ya sea sobre el terreno o la mesa de negociaciones.

El apoderamiento estructural tiene incidencia al inicio del proceso cuando la mediación de la LA sufrió la injerencia de los países del CCG y perdió su percepción de imparcialidad, pero cobra especial importancia en 2017 con el proceso de Astaná, que no solo carece de imparcialidad en sí mismo en razón a las agendas parciales de sus 
promotores, sino que compite con Ginebra y usurpa su unidad de acción, alejando el canal diplomático principal de la órbita de la ONU. En cualquier caso, la consecuencia es un proceso frágil, debido a los comportamientos spoiling empleados por régimen y oposición, acompańados de una estructura internacional y regional polarizada cuyas potencias, en última instancia, también son protagonistas de estos comportamientos que atacan el proceso y dejan al mediador con un escaso margen de actuación.

\section{Referencias}

Aggestan, Karin. 2012. «Prolonged peace negotiations. Spoiler's game», en Guy Olivier Faure. Unfinished business: Why international negotiations fail? Athens: University of Georgia Press.

Álvarez-Ossorio, Ignacio. 2016. Siria. Revolución, sectarismo y yihad. Madrid: Catarata. Asseburg, Muriel, Wolfram Lacher y Mareike Transfeld. 2018. Mission Impossible? UN Mediation in Libya, Syria and Yemen. Disponible en: https://bit.ly/3mLcOcl.

Blaydes, Lisa y Jennifer De Maio. 2010. «Spoiling the Peace? Peace Process Exclusivity and Political Violence in North-Central Africa», Civil Wars, 12 (1): 3-28. Disponible en: https://doi.org/10.1080/13698249.2010.484896.

Cochrane, Feargal. 2008. Ending Wars. Oxford: Polity Press.

Consejo de Seguridad. 2017. 27 September Security Council Briefing on the Situation in Syria, Special Envoy Staffan de Mistura. Disponible en: https:/www.un.org/ und pa/ru/node/184056.

Conversi. Daniele. 2006. "Why do peace processes collapse? The Basque conflict and the three-spoilers perspective», en Edward Newman y Oliver Richmond (eds.), Challenges to Peacebuilding: Managing Spoilers during Conflict Resolution. Tokio: United Nations University Press.

Escola de Cultura de Pau. 2018. Negociaciones de paz 2018. Análisis de tendencias y escenarios. Barcelona: Icaria.

Golan, Galia y Gilead Sher. 2019. Spoiling and Coping with Spoilers: Israeli-Arab Negotiations. Bloomington: Indiana University Press. Disponible en: https://doi. org/10.2307/j.ctvj7wnz6.

Greenhill, Kelly y Solomon Major. 2007. "The Perils of Profiling: Civil War Spoilers and the Collapse of Intrastate Peace Accords», International Security, 31 (3): 7-40. Disponible en: https://doi.org/10.1162/isec.2007.31.3.7.

Greig, Michael. 2013. «Intractable Syria? Insights from the Scholarly Literature on the Failure of Mediation», Penn State Journal of Law and International Affairs, 2 (1): 48-56.

Harland, David y Dareen Khalifa. 2019. Interview. Moving forward: Geir O. Pedersen on developments in Syria. Disponible en web: t.ly/L17jg.

Hinnebusch, Raymond y Omar Imady. 2017. «Syria’s Reconciliation Agreements», The Day After: Post-Uprising Realities and Challenges, 9 (2): 1-14. Disponible en: https://ojs.st-andrews.ac.uk/index.php/syria/article/view/1558/1193. 
Hinnebusch, Raymond, William Zartman, Elizabeth Parker-Magyar y Omar Imady. 2016. UN Mediation in the Syrian Crisis: From Kofi Annan to Lakhdar Brahimi. Disponible en: https://bit.ly/2TL318u.

Licklider, Roy. 2001. "Obstacles to Peace Settlements», en Chester Crocker, Fen Olser Hampson y Pamela Aall (eds.), Turbulent Peace: The Challenges of Managing International Conflict. Washington DC: United States Institute of Peace Press.

Lund, Aron. 2013. Can Iran Go to Geneva II Without Endorsing Geneva I? Disponible en: https://carnegie-mec.org/diwan/54046 [Consulta: 8 de enero de 2020].

Lundgren, Magnus. 2019. Mediation in Syria, 2016-19: A tale of two processes. Disponible en: t.ly/pwdBE. Disponible en: https://doi.org/10.2139/ssrn.3507785.

Newman, Edward y Oliver Richmond. 2006. «Introduction. Obstacles to peace processes: Understanding spoiling», en Edward Newman y Oliver Richmond (eds.), Challenges to Peacebuilding: Managing Spoilers during Conflict Resolution. Tokio: United Nations University Press.

Nilsson, Desirée. 2008. «Partial Peace: Rebel Groups Inside and Outside of Civil War Settlements», Journal of Peace Research, 45 (4): 479-495. Disponible en: https:// doi.org/10.1177/0022343308091357.

Nilsson, Desirée. 2012. «Anchoring the Peace: Civil Society Actors in Peace Accords and Durable Peace», International Interactions: Empirical and Theoretical Research in International Relations, 38 (2): 243-266. Disponible en: https://doi.org/10.108 0/03050629.2012.659139.

Nilsson, Desirée y Mimmi Söderberg. 2011. «Revisiting an Elusive Concept: A Review of the Debate on Spoilers in Peace Processes», International Studies Review, 13 (4): 606-26. Disponible en: https://doi.org/10.2307/41428860.

ONU. 2012a. «Letter dated 24 January 2012 from the Secretary-General addressed to the President of the Security Council» S/2012/71, 30 de enero. Disponible en: https://undocs.org/S/2012/71.

ONU. 2012b. «Resolución 2042 (2012), aprobada por el Consejo de Seguridad en su 6751. a sesión, celebrada el 14 de abril de 2012». S/RES/2042, 14 de abril. Disponible en: https://undocs.org/en/S/RES/2042(2012).

ONU. 2012c. «Resolución 2043 (2012), aprobada por el Consejo de Seguridad en su 6756. a sesión, celebrada el 21 de abril de 2012». S/RES/2043, 21 de abril. Disponible en: https://undocs.org/es/S/RES/2043(2012).

ONU. 2012d. «Informe del Secretario General relativo a la aplicación de la resolución 2043 (2012) del Consejo de Seguridad». S/2012/523, 6 de julio. Disponible en: https://digitallibrary.un.org/record/730415.

ONU. 2012e. "Carta de fecha 10 de agosto de 2012 dirigida al presidente del Consejo de Seguridad por el secretario general». S/2012/618, 10 de agosto. Disponible en: https://undocs.org/es/S/2012/618.

ONU. 2012f. «Resolución 2059 (2012) Aprobada por el Consejo de Seguridad en su 6812. a sesión, celebrada el 20 de julio de 2012S/RES/2059 (2012)». S/RES/2059 (2012), 20 de julio. Disponible en: https:/undocs.org/es/S/RES/2059(2012). 


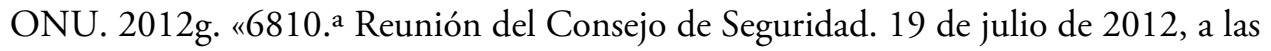
10.25 horas, NY». S/PV.6810. Disponible en: https://undocs.org/es/S/PV.6810.

ONU. 2012h. What's in blue. Insights on the work of the UN Security Council. Syria Consultations. Disponible en: t.ly/yqBK2.

ONU. 2012i. UN Guidance for effective mediation. Disponible en https://peacemaker. un.org/guidance-effective-mediation.

ONU. 2013. «Remarks made by Lakhdar Brahimi, the Joint Special Representative for Syria, following his meeting with Russian Foreign Minister Sergey Lavrov». 06 September. Disponible en: t.ly/GxDVb [Consulta: 11 de enero de 2020].

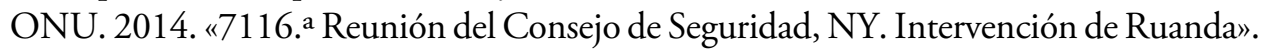
S/PV.7116, 22 de febrero. Disponible en: https://undocs.org/S/PV.7116.

ONU. 2017a. "Implementation of Security Council Resolutions 2139 (2014), 2165 (2014), 2191 (2014), 2258 (2015) and 2332 (2016). Report of the Secretary-General», S/2017/144, 16 de febrero. Disponible en: https://undocs.org/es/S/2017/144.

ONU. 2017b. «Implementation of Security Council resolutions 2139 (2014), 2165 (2014), 2191 (2014), 2258 (2015) and 2332 (2016). Report of the Secretary-General», S/2017/244, 22 de marzo. Disponible en: https://undocs.org/es/S/2017/244.

ONU. 2017c. «Implementation of Security Council resolutions 2139 (2014), 2165 (2014), 2191 (2014), 2258 (2015) and 2332 (2016). Report of the Secretary-General», S/2017/339, 19 de abril. Disponible en: https://undocs.org/S/2017/339.

ONU. 2017d. "United Nations Security Council. Seventy-second year. $7921^{\text {st }}$ meeting. Wednesday, 12 April 2017, 10 a.m. New York» S/PV.7921, 12 de abril. Disponible en: https://undocs.org/S/PV.7921.

ONU. 2019. «8628 ${ }^{\text {th }}$ Security Council meeting. Monday, 30 September 2019, 10 a.m. NY»S/PV.8628. Disponible en https://undocs.org/es/S/PV.8628.

Ortagus, Morgan. 2019. On the Syrian Constitutional Committee in Geneva. Press statement. US Department of State. Disponible en: t.ly/R9Dqq [Consulta: 9 de enero de 2020].

Pearlman, Wendy. 2009. «Spoiling Inside and out: Internal Political Contestation and the Middle East Peace Process», International Security, 33 (3): 79-109. Disponible en: http://www.jstor.org/stable/40207142.

Reiter, Andrew. 2016. Fighting over peace. Spoilers, Peace agreements, and the strategic use of violence. Massachusetts: Palgrave Macmillan. Disponible en: https://doi. org/10.1007/978-3-319-40102-7.

Richmond, Oliver. 2006. "The linkage between devious objectives and spoiling behavior in peace processes», en Edward Newman y Oliver Richmond (eds.), Challenges to Peacebuilding: Managing Spoilers during Conflict Resolution. Tokio: United Nations University Press.

Schneider, Tobias y Theresa Lütkefend. 2019. Nowhere to Hide. The Logic of Chemical Weapons Use in Syria. Disponible en: t.ly/B981B.

Stedman, Stephen. 1997. "Spoiler problems in peace processes», International Security, 22 (2): 5-53. Disponible en: https://doi.org/10.1162/isec.22.2.5. 
Syrian Archive. 2019. Database of Chemical Weapons Attacks. Disponible en: https:// syrianarchive.org/en/collections/chemical-weapons/database.

Syrian National Council. 2020. Issues: Arab League Initiative. Disponible en: t.ly/L132W.

The Carter Center. 2016. The Cessation of Hostilities. April 21, 2016. Disponible en: t.ly/3dn2v.

Wezeman, Peter. 2013. "Arms transfers to Syria», en SIPRI, SIPRI Yearbook 2013. Armaments, disarmaments and International Security. Oxford: Oxford University Press. Disponible en: https://www.sipri.org/yearbook/2013.

Zahar, Marie-Joëlle. 2003. "Reframing the Spoiler Debate in Peace Processes» en John Darby y Roger MacGinty (eds.), Contemporary making: Conflict, Violence and Peace Processes. Basingstoke: Palgrave Macmillan.

Zahar, Marie-Joëlle. 2006. «Understanding the violence of insiders: Loyalty, custodians of peace, and the sustainability of conflict settlement», en Edward Newman y Oliver Richmond (eds.), Challenges to Peacebuilding: Managing Spoilers during Conflict Resolution. Tokio: United Nations University Press.

Zartman, William, Ashraf Mousa y Andrea Schmidt-Colinet. 2019. «Post-uprising excavations», Syria Studies, 11 (2): 1-43.

Presentado para evaluación: 19 de marzo de 2020.

Aceptado para publicación: 4 de agosto de 2020.

\section{JUSAIMA MOAID-AZM PEREGRINA}

juseima@hotmail.com

Doctoranda del Departamento de Ciencia Política y de la Administración de la Universidad de Granada. Es graduada en Derecho y Ciencias Políticas. Sus principales líneas de investigación versan sobre los procesos de cambio político, los conflictos armados y la mediación internacional. Tiene concedido actualmente un contrato predoctoral FPU (FPU18/04917) del Ministerio de Universidades. 